\title{
NEURO-MUSCULAR INCOORDINATION AT THE CARDIA IN THE NEWBORN
}

\author{
BY \\ JOHN THOMSON, M.D., D.P.H., D.C.H. \\ From the Department of Child Life and Health, Edinburgh University
}

(Received for Publication, April 28, 1949)

Hurst (1915) coined the word achalasia, i.e. absence of relaxation, to describe a neuro-muscular incoordination in the alimentary tract. Previously, Rolleston (1896) had suggested such an incoordination to explain some cases of dilatation of the oesophagus. The condition was then known as cardiospasm, a word introduced in 1882 by Mikulicz (1904). Earlier it was known as simple or idiopathic dilatation of the oesophagus and had been described by Hannay (1833). While most of the writings on the subject refer to later childhood and maturity, the presence of the condition in infancy has long been recognized. Rotch (1896) described simple dilatation of the oesophagus in a girl who died aged ten weeks. Luschka (1868) recorded what he considered to be congenital dilatation of the oesophagus, and Zenker (1878) reported the appearance of dilatation of the oesophagus above the cardia in a premature infant of seven months gestation, who died at the age of seven days as a result of haemorrhage from the umbilicus.

Recognition of the condition in the neonatal period has been rare, though many of the cases diagnosed at a later age gave a history of vomiting from birth or soon after (Langmead, 1919; Morgan, 1911).

Tyson (1926) was the first to record a case of achalasia in the neonatal period. He called it phrenospasm. Birnberg (1929) published three cases of cardiospasm. Segar and Stoeffler (1930) recorded two cases. Olmsted (1931), Bogert (1933), and Vinson (1945) reported one case each. Aikman (1933) recorded four cases. The main features of these cases, all of which were diagnosed radiologically, are given in Table 1. A case of uncontrollable vomiting from the second day of life onwards and recorded by Garrahan and Muzio (1932) has not been included in this table. There is some doubt about the diagnosis of this case and no supporting radiological evidence appears to have been obtained at the time of the illness. In an extensive search of the literature no cases other than these were found. This relative infrequency with which the condition in the newborn infant has been recorded, is justification for recording the following three cases of neuro-muscular incoordination. The first two cases appear to be typical of achalasia of the cardia, but the third case is different and requires separate discussion.

\section{Case Reports}

Case No. 1. Baby $\mathrm{O}^{*} \mathrm{H}$., born on January 4, 1949, was a full-time female infant weighing $7 \mathrm{lb}$. $15 \frac{1}{2} \mathrm{oz}$. at birth. She was the result of a second pregnancy; the parents were unrelated. A twenty-two-hour labour was terminated successfully in a difficult delivery with Kielland's forceps. The infant was in poor condition, but revived satisfactorily under treatment, which included lobeline $1 \mathrm{ml}$. and 'synkavit' $1 \mathrm{ml}$., both given intramuscularly, and continuous oxygen therapy. As a prophylactic measure an initial dose of 30,000 units of penicillin was given intramuscularly and followed by doses of 10,000 units at three-hour intervals until 190,000 units had been given.

Feeding was begun with a $7 \%$ solution of lactose water. This was taken well. On the second day no clinical signs of cerebral trauma were observed but the infant vomited once a little brownish, blood-stained mucus. Meconium was passed normally. On the third day vomiting during and immediately after feeding became troublesome. It was not forceful. Gastric lavage was carried out. For this purpose a soft rubber catheter was passed into the stomach. In doing this, no obstruction was felt and no difficulty was experienced. Improvement of short duration followed the gastric lavage, which was repeated on the fourth day. On that day expressed breast milk was added to the diet. On the fifth day, following a short period of improvement, vomiting during and following feeding recurred. The vomiting was not forceful or projectile. Dehydration became more obvious. The temperature rose to $101^{\circ} \mathrm{F}$. The infant continued to feed eagerly but would regurgitate the complete feed unaltered within two minutes of taking it. There was no dysphagia. Ordinary clinical examination showed no cause for the 


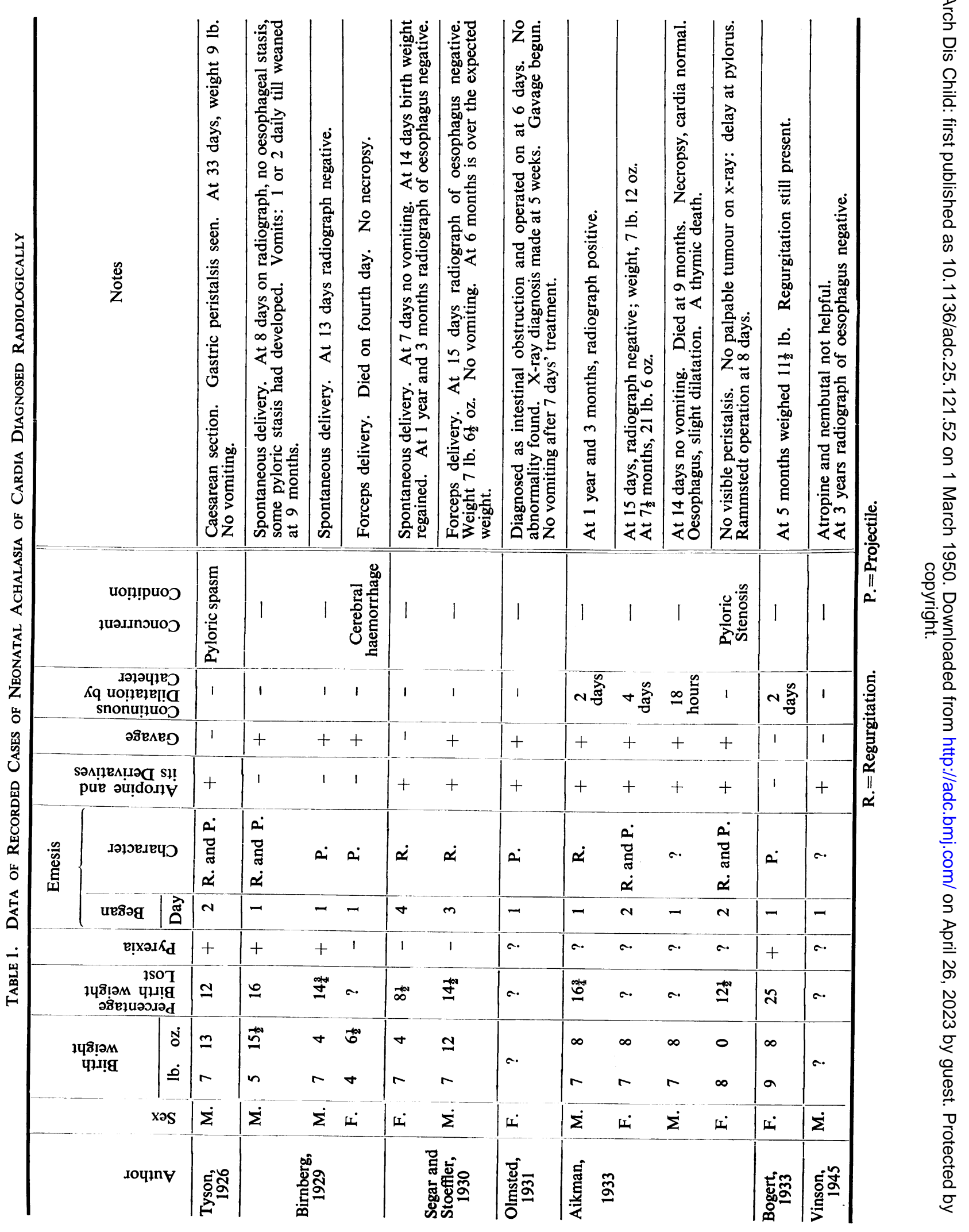




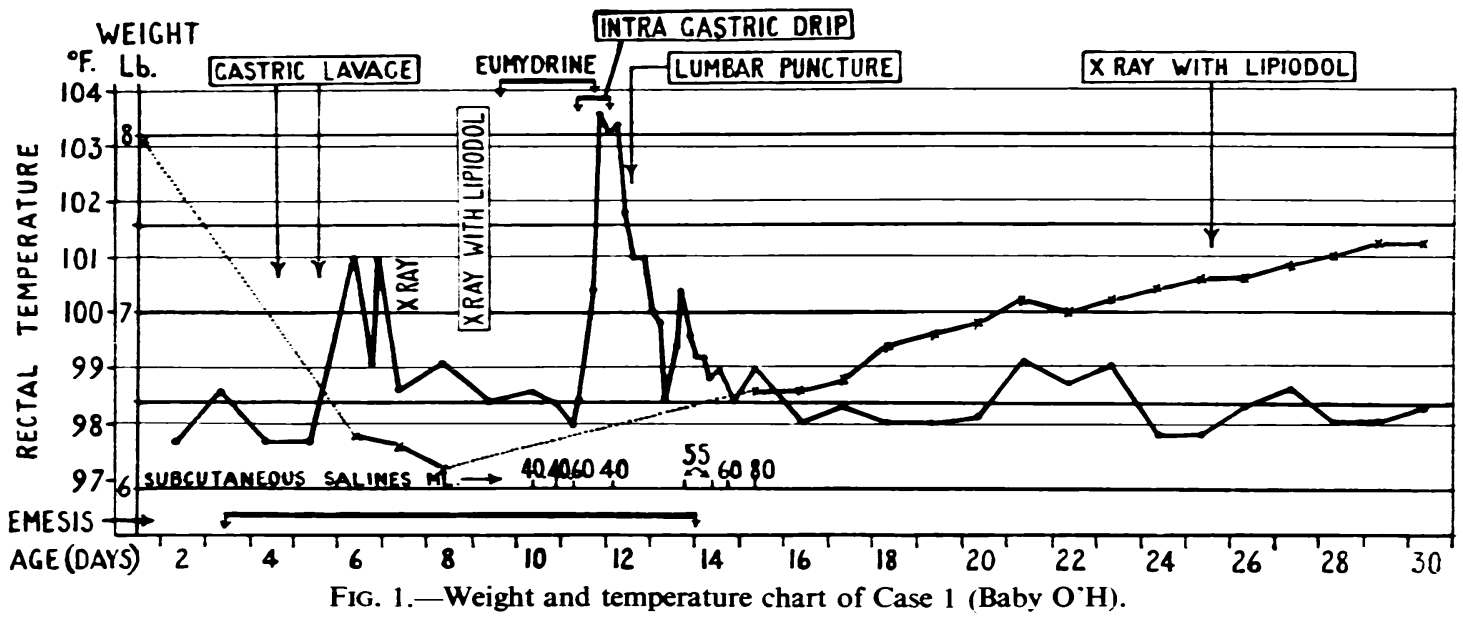

vomiting and radiological examination of the thorax was negative. Loss of weight had become marked, so that by the seventh day a loss of $23 \%$ of the birth weight had occurred (Fig. 1).

After giving $10 \mathrm{ml}$. of lipiodol, radiological examination was repeated (Fig. 2). This revealed narrowing at the lower end of the oesophagus which was dilated in its upper and middle thirds. A catheter was passed into the stomach (Fig. 3). This demonstrated the absence of an organic obstruction and allowed the lipiodol to enter the stomach which emptied rapidly. The bulk of the lipiodol was in the small bowel within 15 minutes.

In an effort to overcome this functional obstruction, 'eumydrin' was given in $0.5 \mathrm{mg}$. doses before

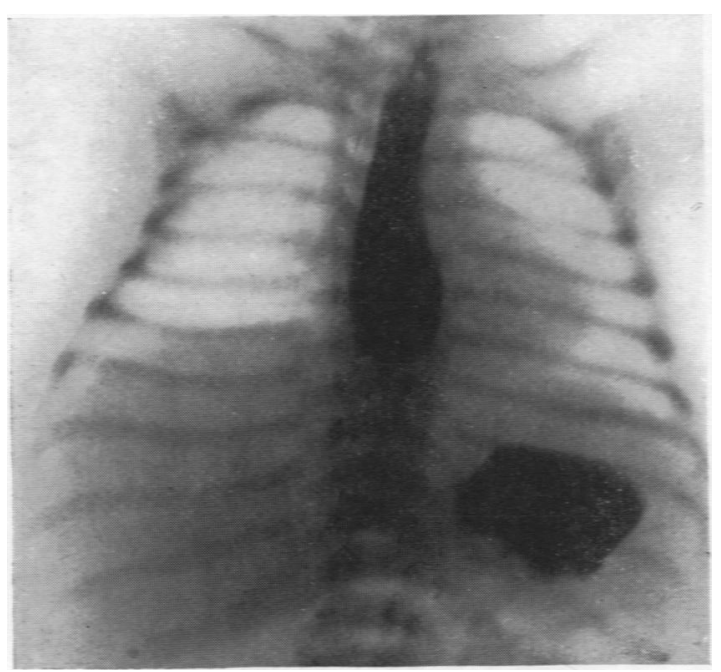

Frg. 2.-Radiograph with lipiodol of Case 1. Anterior view showing dilatation of oesophagus in upper two-thirds and partial obstruction in the lower third.

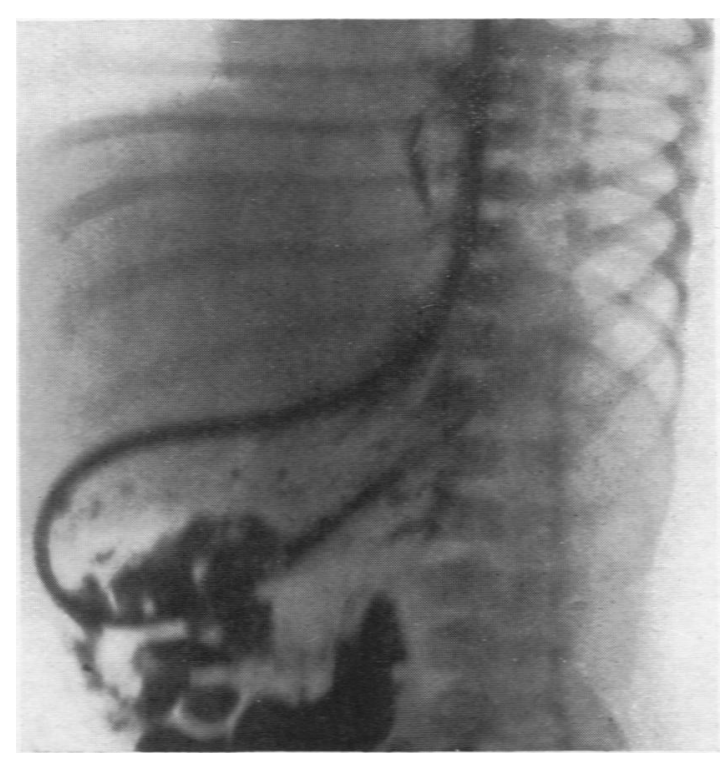

FK. 3.-Lateral view of Case 1 with catheter in oesophagus and stomach. Note the persistence of the oesophageal dilatation when oesophagus is practically empty.

food, and routine feeding by gavage was begun. Subcutaneous salines were also given. Towards the end of the tenth day the vomiting became more projectile and a continuous intragastric drip was substituted for gavage. The infant did not tolerate the drip well and vomited the tube once. Following the occurrence of two cyanotic attacks the drip was removed. It had been used for approximately 15 hours. At the same time intolerance to ' eumydrin' developed. The first signs were restlessness and alertness. These were followed by pyrexia (Fig. 1) and later some stiffness of the neck 


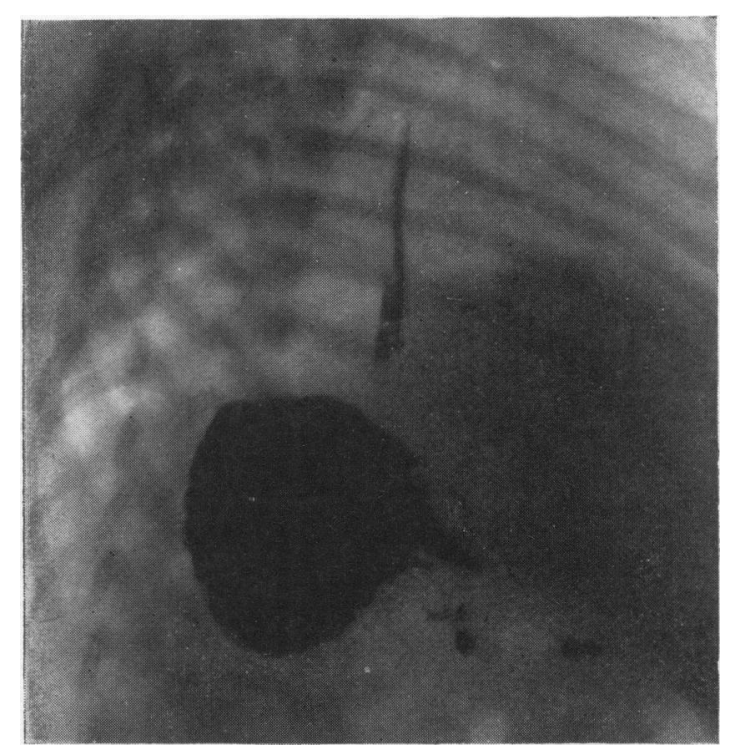

FIG. 4.-Radiograph (lateral view) with lipiodol of Case 1. Shows absence of oesophageal obstruction and outlines the distal end of the oesophagus.

muscles. The 'eumydrin' was discontinued. A lumbar puncture demonstrated a clear cerebrospinal fluid, not under pressure, and sterile on culture.

Gavage was continued for 18 hours following the removal of the intragastric drip. Thereafter ordinary bottle feeding was begun. At intervals of two hours, $1 \frac{1}{2} \mathrm{Oz}$. of $1 / 12$ dilution of sweetened condensed milk was given. The infant fed well and was fed slowly. Of the first ten feeds thus given, one was entirely vomited, about $\frac{1}{2} \mathrm{oz}$. of another was returned, and a mouthful of all the others except one, which was entirely retained. The amount and strength of the feeds were increased slowly, but no further vomiting of any note occurred. Subcutaneous salines were discontinued on the fourteenth day. Following a negative radiological examination (Fig. 4) on the twenty-fourth day, feeding at three-hour intervals was begun. The infant was discharged when 36 days old. She weighed $7 \mathrm{lb}$. $8 \frac{1}{2} \mathrm{oz}$. She was then taking a 4-oz. feed in average time. There was no vomiting. She weighed $10 \mathrm{lb}$. when 11 weeks old.

Case No. 2. Baby C. was a full-time, spontaneously delivered female infant who weighed 6 lb. 3 oz. when born on Sept. 13, 1946. She was an illegitimate child of unrelated parentage. Her condition at birth was good. The passage of meconium was normal. On the second day she began to vomit. The vomiting occurred during and immediately after feeding. It was not forceful. The vomitus consisted of brownish mucoid material

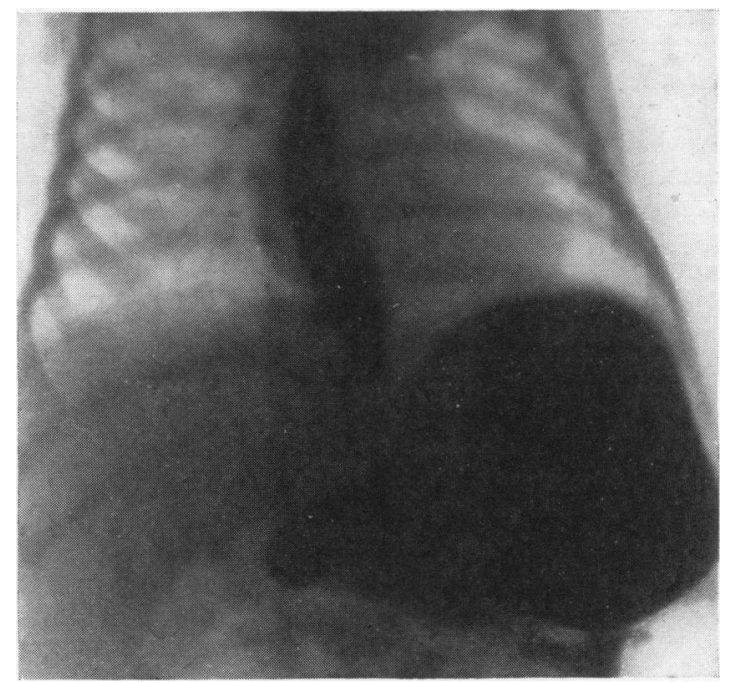

FIG. 5.-Partial side view of Case 2. Compare with Fig. 2.

mixed with milk, but by the end of the third day unaltered food only was returned. Gastric lavage was carried out on the third and fifth days. A soft rubber catheter was used for this purpose and no difficulty was encountered in passing it. The

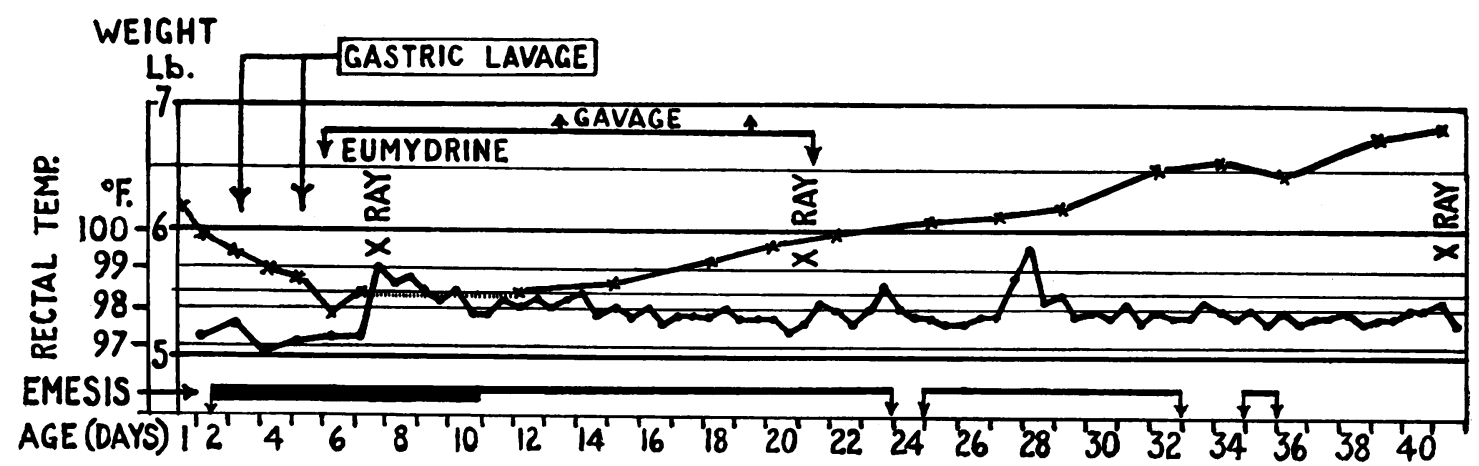

FIG. 6. - Chart of Case 2 (Baby C.) to show progress and treatment. 
gastric lavage did not appear to lessen the incidence of the vcmiting.

On the sixth day the vomiting became more forceful in character. Medication with 'eumydrin', $0.5 \mathrm{~m}$. . tefore food, was tegun. Next day radiological examination with barium disclosed a dilated oesophagus with some functional delay at the cardia. Scme food did pass into the stomach but was again delayed at the pylorus. No gastric peristalsis was seen and no pyloric tumour was felt (Fig. 5). The infant was now fed on a 1/10 mixture of a sweetened condensed milk which was thickened by the addition of a predigested food. The feed was given slowly and when it was finished the infant was laid on the right side. The feeds were taken eagerly and there was little evidence of dehydration. The lowest recorded weight showed a loss of only $9.5 \%$ of the birth weight (Fig. 6). By the tenth day the incidence of the vcmiting had diminished somewhat and an occasional whole feed was retained. Four or five vomits a day would occur and two of these would be projectile. The projectile vomits occurred up to one hour after the feed had been given.

The infant did no more than hold her own during the first week of "eumydrin' medication. Accordingly, gavage was tegun on the thirteenth day and continued for one week. This resulted in a diminution of the numter of vomits, which became regurgitant in character, and 'eumydrin' was stopred on the twenty-second day. The infant continued to make satisfactory progress though regurgitation did not cease until it was five weeks old. A minor respiratory infection on the twenty-seventh day was successfully treated with oral penicillin.

When six weeks old the infant was discharged to a convalescent home, where after a stay of three weeks, she was removed to a nursery. At 11 weeks old she was returned to hospital suffering from ccnjunctivitis. When seen as an out-patient on this cccasion a rather projectile vomit was observed. In view of her past history the infant was kept under otservation in hospital for three weeks. A barium series done at this time showed no abnormality of the cesophagus and that there was a very slight residuum in the stomach two and a half hours after the barium was given. The infant was discharged aged 14 weeks. The following week the infant was found buried. She had met a violent death, said to be by drowning. Necropsy disclosed no organic obstruction at the cardia or at the pylorus.

Case No. 3. The mother of this infant, Baby L.A., who was born on Dec. 2, 1942, suffered from syphilis. She had an aortic lesion. Her blood Wassermann reaction had been negative for over 12 months before the birth. Anti-syphilitic treatment had been difficult because of intolerance to arsenic, bismuth, and mercury. This was a first pregnancy. The child was full-time but weighed only $5 \mathrm{lb} .9 \frac{1}{2} \mathrm{oz}$. and was $18 \mathrm{in}$. long. The delivery was instrumental owing to maternal and foetal distress.

Following delivery the infant was not in good condition, and four hours later there was a transient but severe cyanotic attack. Respirations were shallow. Some alertness of the facies developed and a little eye-rolling was observed. Vomiting began on the day of delivery. All these signs were considered to be cerebral in origin and the infant was treated accordingly. She was kept quiet, shaded from light, the minimum of handling was permitted, and she was not lifted to be weighed. Chloral hydrate was given. Meconium was passed normally.

Apart from the vomiting all the signs of cerebral irritation disappeared rapidly. The infant fed well and eagerly but continued to vomit. The vomiting occurred 15 minutes after a feed had been finished: it did not occur during a feed. The feed consisted of $1 \frac{1}{2} \mathrm{oz}$. lactose water and $1 \mathrm{oz}$. breast milk. It was not recorded whether the vomitus contained altered milk or gastric secretion. The infant visibly lost weight and gradually assumed a marasmic appearance. The maximum recorded loss of weight was at 15 days, by which time $22^{\circ} \%$ of the birth weight had been lost (Fig. 7). On the thirteenth day a lumbar puncture disclosed a clear cerebrospinal fluid not under-pressure, and intracranial trauma was dismissed as a cause of the vomiting.

The infant was examined radiologically when

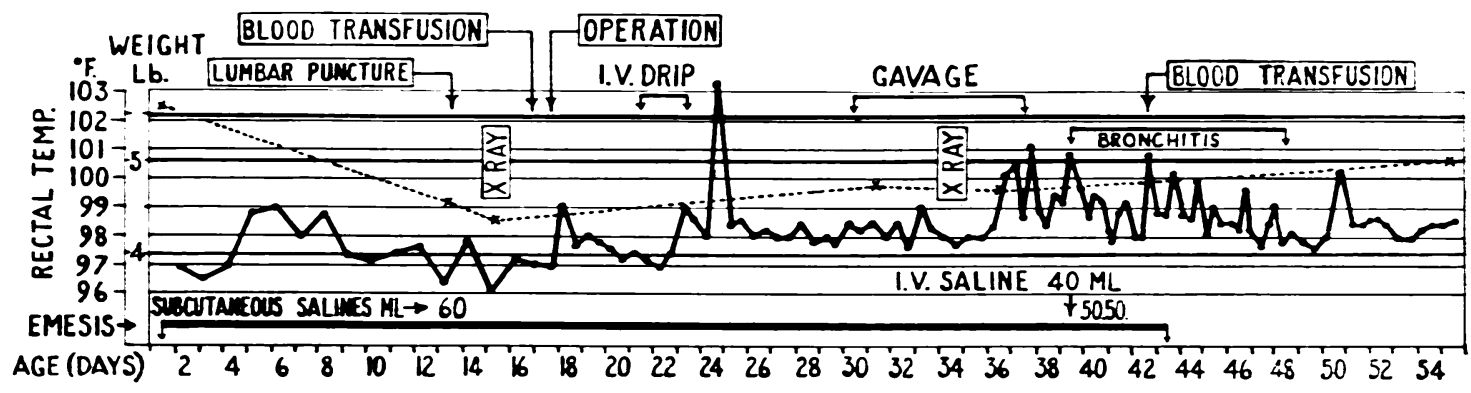

Fig. 7.-Chart of Case 3 (Baby L.A.) to show progress and treatment. 


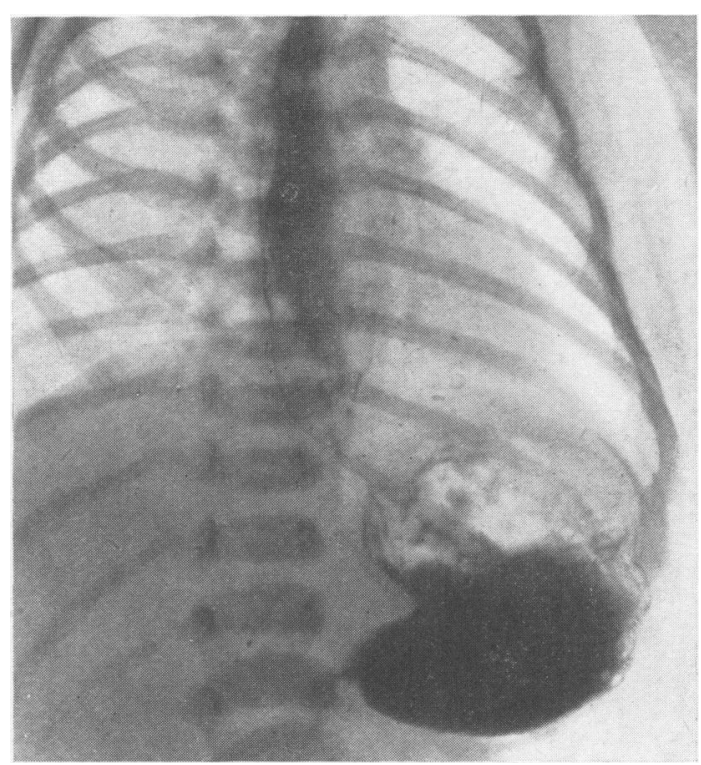

FIG. 8.- Radiograph of Case 3. Barium has gravitated to the pyloric end of the stomach, and oesophageal contents can be seen streaming across the air-filled cardiac end of the stomach. Compare with Fig. 2 (Case 1).

15 days old. The radiologist reported that 'after 90 minutes there is still some barium in the oesophagus and it is present in all films. This would suggest a partial obstruction in the lower third. Barium has entered the small intestine' (Figs. 8,9 , and 10).

Because of the infant's critical condition she was transferred to a surgical ward, and following preparation which included a blood transfusion, gastrostomy was performed on the seventeenth day. A number eight rubber catheter was stitched into the stomach. Through this catheter the stomach was washed out with normal saline and $2 \mathrm{dr}$. (7 c.cm.) of saline left in. There was a small post-operation vomit. The gastrostomy catheter was used for feeding and during the 48 hours following the operation feeds of $2 \mathrm{dr}$. $(7 \mathrm{c.cm}$.) in amount were given. At first, sterile water was used and later saline feeds were alternated with feeds of glucose water. The vomiting continued but was less in amount and frequency. The quantity of the feeds was gradually increased, a $50 \%$ milk and water mixture being given. With the larger feeds there was an increase in the vomiting and the condition of the infant deteriorated. The progress notes describe the infant as being 'almost moribund'. Although some convulsive seizures appeared, the condition of the infant improved steadily following an intravenous drip of glucose saline which was set up on the twenty-first day, four days after gastrostomy. Fifteen ounces of glucose saline were given in 36 hours. The cause of the seizures was not determined.

Gavage feeding was begun 13 days after gastrostomy. On the same day the case notes state, 'A no. 10 catheter was passed down the oesophagus. Great difficulty was experienced when the tip reached the lower end of the oesophagus. The catheter was passed twice daily thereafter, with increasing ease each time'. After five days of gavage, a second radiological examination was made. The radiologist reported 'no obstruction or abnormality of the oesophagus on swallowing barium. No retention in the oesophagus, but a slight tendency to regurgitation. Some delay in emptying from the stomach-up to 20 hours-but no hold-up in small or large intestine'. Within 48 hours of the radiological examination the infant became febrile, and later a well-marked bronchitis was apparent. (In considering this phase of the illness, the possible inhalation of barium must be kept in mind.) The condition of the infant again deteriorated. Hypodermoclysis and venoclysis were necessary and finally a blood transfusion was given.

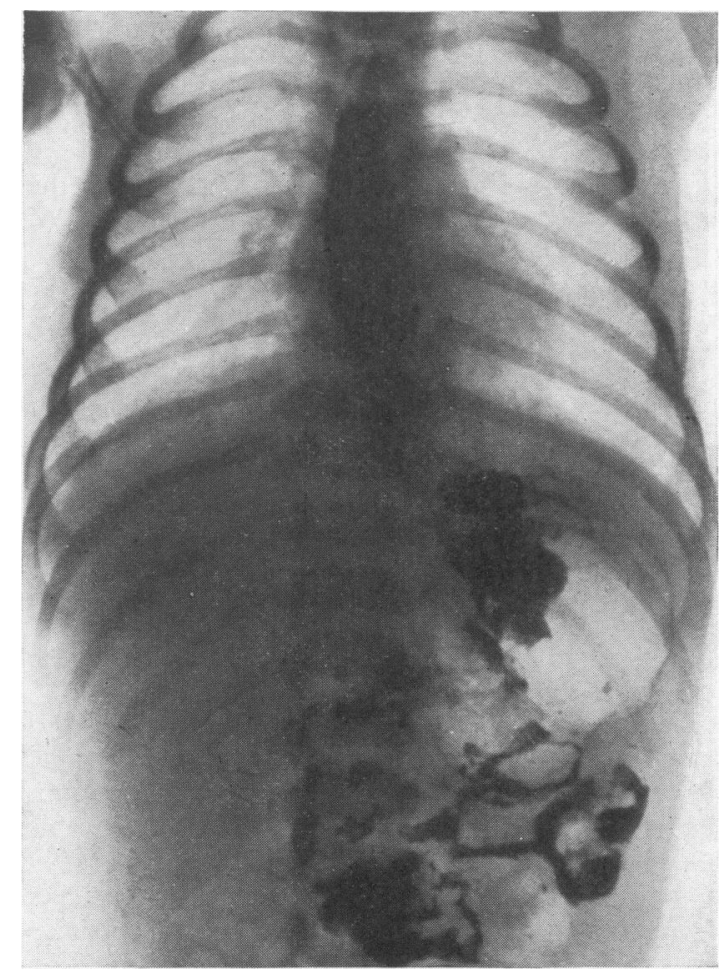

FIG. 9.-Radiograph taken 35 minutes after Fig. 8. Shows an increase in the amount of barium in the oesophagus compared with Fig. 8. There is free passage of barium into the small bowel. Note the irregular outline of the lower end of the oesophagus compared with Figs. 2 and 5. 


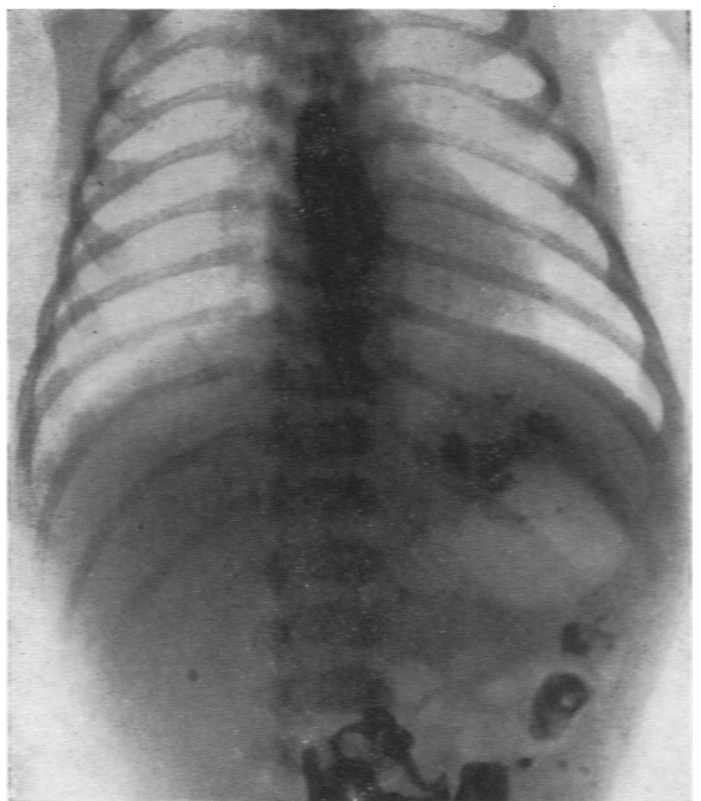

Fig. 10.-Radiograph taken 80 minutes after Fig. 8. Note the presence of regurgitated barium in the oesophagus.

The temperature subsided gradually and about the same time the vomiting ceased. She was discharged from hospital when eight weeks old and weighed $5 \mathrm{lb}$. The gastrostomy tube was removed, but the date on which this was done is not given in the case notes.

The infant's subsequent history shows that at 16 weeks and 29 weeks she weighed $9 \mathrm{lb}$. and $14 \mathrm{lb}$. respectively. The gastrostomy wound was entirely healed at 16 weeks. At 14 months she was thought to be backward, and at 21 months she was referred to the clinic for mentally defective children. There she was classified as microcephalic. She was last seen at that clinic when 3 years, 3 months old.

\section{Discussion}

Reference to Table 1 shows that achalasia of the cardia in the newborn infant has been found in both sexes and in full-time and immature infants. The presenting sign is vomiting. The day on which this sign appears is variable, as is the character of the vomiting. Factors other than the presence of neuro-muscular incoordination or sympatheticparasympathetic imbalance may account for this. In Case 1 vomiting did not begin until the third day. It is probable that the oesophagus could contain the relatively small and infrequent feeds of $15 \mathrm{ml}$. of $7 \%$ lactose water, which were given. Had the feeds been larger vomiting might have begun sooner, as it did in Case 2, or on the first day, as has been recorded in seven of the cases in Table 1 .

In some instances vomiting becomes more projectile in character. This change was present in four of the recorded cases. The development of pyloric spasm is the reason given in the cases recorded by Tyson (1926), Birnberg (1929), and in my Case 2. In one of Aikman's cases pyloric stenosis was certainly the cause. The remaining one of the four cases referred to was recorded by Aikman, and it resembles Case 1 in that no definite cause can be given for the projectile vomiting, other than oesophageal peristalsis.

It is notable that in four cases only projectile vomiting has been recorded. Cerebral haemorrhage may have been the explanation in one of Birnberg's cases. It is unfortunate that no necropsy was performed on this infant, who died on the fourth day of life. In Olmsted's case, vomiting was sufficiently impressive to give rise to a diagnosis of intestinal obstruction. At operation no obstruction and no cause for the vomiting was found. The vomiting continued after the operation. No explanation of the projectile vomiting was given in the two remaining cases. In three of the recorded cases only regurgitation was observed.

The vomiting occurs during or immediately after feeding. This is not a diagnostic point of great differential importance, since vomiting at this time may also occur in pyloric spasm, pyloric stenosis, complete gastric spasm (Lust, 1925), and in cases of excessive relaxation of the cardia (Neuhauser and Berenberg, 1947). The vomitus in an uncomplicated case of achalasia of the cardia consists of unaltered food. This is not so if either pyloric spasm, pyloric stenosis, or gastric spasm is concurrent. Thus the character of the vomitus is not always a reliable diagnostic point.

In the last resort the diagnosis of achalasia of the cardia depends upon radiological examination. For this purpose lipiodol should be used in preference to barium which was used in all cases recorded so far. The risk of a fatal pneumonia following the inhalation of regurgitated barium ought not to be taken. The first impression one obtains from an inspection of Fig. 2 is that the gap between the lower end of the dilatation of the oesophagus on the one hand, and the gastric shadow on the other, is rather more than one expects to find in achalasia of the cardia. This is accounted for by the relatively greater length of the cardiac portion of the oesophagus in the newborn infant (Hurst, 1925). The unobstructed passage of a catheter into the stomach can also be demonstrated radiologically. This was done in Case 1 (Fig. 3). 
Apart from vomiting, the outstanding feature of achalasia of the cardia in the newborn infant is progressive loss of weight. Exceptionally, this may be severe. In six of the recorded cases it was of the order of $15 \%$ of the birth weight. A loss of $8.5 \%$ in one case and $25 \%$ in another represent the extreme of loss of weight which have been recorded. No record of the loss of weight has been given in five of the cases. In Case 2 the loss of weight was relatively low at $9.5 \%$ of the birth weight, but, in Case 1, $23 \%$ of the birth weight was lost. This large loss of weight is exceeded by the case of Garrahan and Muzio (1932) who recorded a loss of $47 \%$ of the birth weight over a period of 18 days in an infant who weighed $3,000 \mathrm{~g}$. $(6 \mathrm{lb}$. $10 \mathrm{oz}$.) and who recovered. It is to be noted that this infant was born of syphilitic parents and that it had a salvarsan dermatitis.

In the treatment of achalasia of the cardia atropine has been used by five observers (nine cases). No general agreement concerning its efficacy has been expressed and Vinson stated that it was not helpful. In the present instance the 'eumydrin' which was given was not tolerated by Case 1, but seems to have been beneficial in Case 2. Gavage was used by four of the observers (nine cases), but only three observers used gavage and atropine in the same case (six cases). Case 2 was treated in this manner. Continuous dilatation of the cardia by leaving a soft rubber catheter in position was practised by two authors (four cases). In three of Aikman's cases this treatment was combined with atropine and gavage before and after the period of continuous dilatation. In Case 1 this procedure was also followed.

The prognosis of achalasia of the cardia in the neonatal period is good. The two deaths which have been recorded were not attributable to achalasia of the cardia. In two cases regurgitation of lesser degree continued till nine months and five months respectively. The latter of these two cases was only $2 \mathrm{lb}$. over its birth weight when it was five months old (Bogert, 1933). One case with a positive radiograph at 15 months is reported by Aikman. In the present instances a cure appears to have been obtained, as in the remaining eight recorded cases. The death of Case 2 was attributable to violence, and the necropsy produced no evidence of an obstructive lesion.

First consideration of the history of Case 3 gives the impression that an oesophageal obstruction was the cause of the vomiting. The first $x$-ray report 'suggests' that there is an oesophageal obstruction, and the surgeon's report of 'great difficulty' in passing a catheter through the lower end of the oesophagus is supporting evidence. It is difficult to correlate these findings with vomiting following feeds given by gastrostomy tube. The idea is engendered that there may have been no oesophageal obstruction, but rather a pyloric one.

Inspection of the $x$-ray photographs upon which the first $x$-ray report is based is of considerable interest. After giving barium, three photographs were taken in rapid succession. The third of these is reproduced (Fig. 8). It shows a relatively small stomach which has very free communication with the oesophagus. There is an excellent demonstration of the oesophageal contents streaming across the air-filled cardiac end of the stomach towards the pyloric end, to which the barium meal has already gravitated. A further photograph taken 35 minutes later shows that some barium has passed into the small bowel, and that there is a considerable amount of barium in the oesophagus (Fig. 9). This has been interpreted as delay in emptying the oesophagus.

Comparison of Fig. 8 with Fig. 9 shows without doubt that there is less barium in the oesophagus in the first of these two photographs. No additional barium had been given. Regurgitation from the stomach is the only means by which the appearance seen in the later photograph can be explained. It may be that there is some pyloric spasm present. Another photograph taken 90 minutes after administration of barium shows some barium still in the oesophagus (Fig. 10). This interpretation of the first series of $x$-ray photographs is similar to the report given on the second series.

The infant was fed by gavage for four days before the taking of the second series of photographs. No difficulty was experienced with gavage so that the tube used cannot be considered to have dilated a stricture. Also before the second series of photographs a number ten catheter was passed into the stomach twice a day, eight times in all. This was done blindly. ' Great difficulty' was experienced on the first occasion, but it was passed 'with increasing ease each time'. Since vomiting persisted after this treatment it may be doubted whether any pre-existing stricture was dilated.

In reviewing the diagnosis of this case one may consider whether excessive relaxation of the cardia, perhaps accompanied by pyloric stasis or spasm, might account for the illness. Hitherto, excessive vomiting because of an undue relaxation of the cardia has not been stressed as a serious pathological state in the newborn. It has been recorded in an adult (Berk, 1945). The only reference to the condition in the newborn is that of Neuhauser and 
Berenberg (1947). In routine radiological examinations of 2,000 vomiting newborn infants, these authors found 12 infants who showed marked relaxation of the cardia. In some of these cases, inspiration, crying, and coughing was sufficient to flood the oesophagus with gastric contents. In others the lightest of pressure upon the abdomen produced the same result. This regurgitation sometimes stimulated a gag reflex which resulted in true vomiting. They found that the vomiting usually started in the first few days of life, became progressively worse, and soon occurred with every feed. The vomiting might take place during a feed, but was most apt to occur after the infant was put back in his cot. It is to be noted that the vomiting in Case 3 occurred a quarter of an hour after the feed was finished. The authors treated their worst cases by keeping them in a semi-sitting position day and night, and using a thickened feed. There were no concomitant abnormalities in any of their cases, and it must be noted that none of these patients presented the picture of severe wasting such as was seen in Case 3 . They seem to have responded to the simple nursing technique instituted, but Case 3 was not so treated.

The presence of pyloric spasm in Case 3 is suggested by the second $x$-ray report which states that - there was some delay in emptying from the stomach up to 20 hours'. Before assessing the value of this report, it is essential to know how long it takes the normal newborn infant to empty the stomach. On this point there is surprisingly little authoritative information. In an extensive radiological study made by Henderson (1942) it was shown that the stomach was completely empty at the end of eight hours in $30(27 \cdot 27 \%)$ out of 110 normal newborn infants, and that $40(36 \cdot 36$ $\%$ ) infants had some barium remaining in the stomach at the end of $\mathbf{2 4}$ hours. This suggests that great care should be taken in interpreting a failure to empty the stomach at $\mathbf{2 0}$ hours as a delay. It would appear that in Case 3 there may have been no undue pyloric delay and that excessive relaxation of the cardia with an easily stimulated gag reflex may be an explanation of the illness.

\section{Summary}

Two cases of achalasia of the cardia in the newborn infant are reported.

The literature on achalasia of the cardia in the newborn is reviewed.

A case of vomiting of doubtful origin in the newborn infant is described.

Consideration is given to a diagnosis of excessive relaxation of the cardia, achalasia.

It gives me pleasure to acknowledge access to the hospital record of Case 3 which was in the care of Dr. J. L. Henderson and Miss G. Herzfeld.

\section{REFERENCES}

Aikman, J. (1933). N.Y. St. J. Med., 33, 865.

Berk, M. (1945). Gastroenterology, 5, 290.

Birnberg, T. L. (1929). Amer. J. Dis. Child., 38, 1183.

Bogert, F. van der (1933). Arch. Pediat., 50, 585.

Garrahan, J. P., and Muzio, E. (1932). Sem. méd., 2, 1799.

Hannay, A. J. (1833). Edinb. med. J., 40, 65.

Henderson, S. G. (1942). Amer. J. Roentgen., 48, 30.

Hurst, A. F. (1915). Quart. J. of Med., 8, 300.

- (1925). Brit. med. J., 1, 145.

Langmead, F. (1919). Proc. R. Soc. Med., 13 (Sect. Dis. Child.), 43.

Luschka, H. von. (1868). Virchow's Arch., 42, 473.

Lust, F. (1925). Arch. Kinderheilk., 76, 203.

Mikulicz, J. V. (1904). Dtsch. med. Wschr., 30, 17, and 50.

Morgan, W. G. (1911). Med. Rec. N.Y., 80, 173.

Neuhauser, E. B. D., and Berenberg, W. (1947). Radiology, 48, 480.

Olmsted, H. C. (1931). Amer. J. Dis. Child., 41, 213.

Rolleston, H. D. (1896). Trans. path. Soc., 47, 37.

Rotch, T. M. (1896). 'Pediatrics,' 2, 836. Philadelphia.

Segar, L. H., and Stoeffler, W. (1930). Amer. J. Dis. Child., 39, 354.

Tyson, R. M. (1926). Arch. Pediat., 43, 818.

Vinson, P. P. (1945). J. Pediat., 27, 565.

Zenker, F. A. (1878), in Ziemssen, H. von, 'Cyclopaedia of the Practice of Medicine,' 8, 51, New York. 